\title{
Recent work of the Conference of European Statisticians
}

\author{
Work Session on Costing Aspects of Population and Having Censuses (Geneva, \\ 4 March 1994)
}

This meeting was convened to finalize the contents of a study on costing aspects of population and housing censuses that France, Hungary, Sweden and the United Kingdom conducted the past three years on behalf of the Conference. The study will be submitted to the Conference of European Statisticians at its forthcoming session (June 1994) plenary session and subject to its being approved by the Conference, published in the Conferences Statistical Standards and Studies series in the autumn of 1994.

\section{Meeting on Statistics on Household Income (Geneva, 14-15 March 1994)}

The meeting considered the following items: (i) preparation of regional guidelines on statistics of the distribution of income, consumption and accumulation of households; (ii) development of conceptual foundations for statistics of poverty and other socio-economic statistics; (iii) development of equivalence scales for use in international comparisons; (iv) reconciliation of household income statistics obtained from different sources; (v) selection of methods for compiling household income statistics in varying contexts; (vi) socio-economic accounting; and, (viii) future work.

The meeting confirmed the importance of developing regional guidelines on statistics of the distribution of income, consumption and accumulation of households. ECE and Eurostat were encouraged to join their efforts in advancing work in that regard. Assistance to transition countries in establishing new household income statistics was also regarded as an important element of future work. Towards that end, the ECE secretariat and Eurostat were asked to provide relevant documentation on the European Commission Household Panel (ECHP) Survey to transition countries and other countries outside the European Economic Area. A number of methodological issues were also identified, on which national experiences could be further exchanged. 
Work Session on Statistical Output for Dissimination to Information Media (Oslo, 15-17 March 1994)

The main objective of the meeting was to study implications of the provision of computerized information to media, in particular to press. The following issues have been discussed: (i) organizational and technical aspects of communication between statistical offices, the press and other media; (ii) the use of computerized statistical output in communication with press and other media; and, (iii) feedback from users on the use of computerized statistics in communication with press and other media (report of the work session: $\mathrm{CES} / 808$ ).

Joint ECE/CEC Work Session on Statistics of Environmental Protection Expenditures and Facilities (Geneva, 23-25 March 1994)

The purpose of the work session was to develop a standardized statistical nomenclature for statistics of environmental pollution. The meeting recommended a "Single European Standard Statistical Classification of Environmental Protection Activities and Facilities" for adaptation by the CES in June 1994 (set out in document CES/ 822). The classifications of the meeting are reported in document CES/809. 